\title{
Design of adventure game based on Sanxingdui culture elements
}

\author{
Yu Jianhao ${ }^{1,}$, Zhang Yinfang ${ }^{2, b}$ \\ ${ }^{1}$ Sino-Korean School of Multimedia Design, Shanghai University of Engineering and Science, \\ Shanghai, 201620, China \\ ${ }^{2}$ Sino-Korean School of Multimedia Design, Shanghai University of Engineering and Science, \\ Shanghai, 201620, China
}

aemail: 951550945@qq.com, bemail:zyfang0502@163.com

Keywords: Adventure Game; Sanxingdui Culture; Game Design; Game Development

\begin{abstract}
Traditionally, Chinese traditional culture elements always exert an effect on development of modern Chinese game thanks to its rich visual models and profound intrinsic implication. Sanxingdui culture, with its inheritance, individuality and mystique, has unique culture connotation. The paper used Sanxingdui as design elements of adventure game, made research that is of significant practical significance to promote Sanxingdui culture and put more fun to adventure game.

As a representative archaeological relic of ancient Bashu culture in China, Sanxingdui is quite valuable in terms of cultural inheritance. Meanwhile, when Chinese digital culture industry booms, the combination of rising recreation and traditional culture becomes a hotspot. Till now, the demonstration forms of Sanxingdui are museum exhibition or 3D holographic images. Fewer of them display in way of game. So combining Sanxingdui culture elements with adventure game is also a new attempt.
\end{abstract}

\section{Sanxingdui Culture Elements}

The Sanxingdui culture elements in this paper are taken from Sanxingdui site located on south bank of Xibei Yazihe River in Guanghan city, Sichuan province. It is one of the best-known archaeological findings in the world up to now, and belongs to Yinshang civilization. With first batch excavated by local farmers in 1929, more than 4000 archaeological objects were unearthed successively amid growing scope of intervention by archaeologists. The ones well known to people include bronze mask, divine tree, sunbird, among other bronze ware. The finding of Sanxingdui site is a witness to diversified development of ancient bronze culture in China. In addition, the archaeologists also call Sanxingdui culture as a symbol of Bashu culture, which can refer to broader Bashu culture in ancient history or specifically refer to the generic term of Ba ethnicity site found by current archaeological work. The legion of bronze statues and masks reveal daring and lively imagination of ancient Shu people and the culture custom of worshipping deceased mother, ancestor and God.

The masks share characters of wide eyebrow, bulging eyes, big nose, thick lips and bat ear, forming overblown and abstract images, which are no human or ghost and combine deity and spiritualism, mainly serving as ritual ware, sacrificial vessel and royal burial accessories. Furthermore, in the site, bronze wares decorated with "bird" shape were found, such as bronze divine tree, on which there are altogether nine birds. Estimated by the archaeologist in archaeological work, these birds are related to apollo worshipping culture. The Songs of Chu Asking heaven records "Yao ordered Yi to shoot the sun, who hit nine, and in the center of each sun was three-foot bird". There existed a recording of "On sun valley is sun, arriving by one day and going out by one day, borne by bird". The relevancy between bird and sun was also recorded in the Classic of Mountains and Rivers. Meanwhile, divine tree itself also implies holy place where God and people communicate. 


\section{Design of Game Named “Cavity in Ancient Yu” based on Sanxingdui Culture Elements}

This is a 2D horizontal version flat-style adventure game run on mobile platform, developed using unity, relating a little hero coming to Ancient $\mathrm{Yu}$ from contemporary age and getting through levels in a series of adventure in Sanxingdui site.

\section{Game Planning}

In early period, the game set the modern and ancient times as adjacent point. In ancient Yu time, the nine sunbirds governing heaven and earth on ancient mulberry God tree lost part of body due to man-made sabotage, resulting in damage to balance of heaven and earth, with frequent natural disasters everywhere. To rescue ancient $\mathrm{Yu}$, a people in the future world must be summoned to collect the broken sunbird fragments to restore the divine tree. So Cancong, the ruler of ancient $\mathrm{Yu}$ summoned a knapsack little hero to ancient Yu using supernatural power, granted him the Sanxingdui mask headgear on head as base for action in ancient $\mathrm{Yu}$, and gave him the mission of rescuing ancient $\mathrm{Yu}$. Then the little hero began his adventure.

Game framework is as shown in Figure 1. The game starts with the animation that introduces the game background. On the main interface are "Setting”, "Start Game” and "About us" buttons. Click "Start Game" button to enter the interface, which let player choose levels marked in regional map (altogether 3 levels). The little hero collects gold coins in each level to increase points and avoid obstacles in order to pass the game. And when he run into obstacles and fails, game returns to regional map interface and tell the player to restart game for the same level or select other levels. After passing all the 3 levels, game returns to main interface and resume the game.

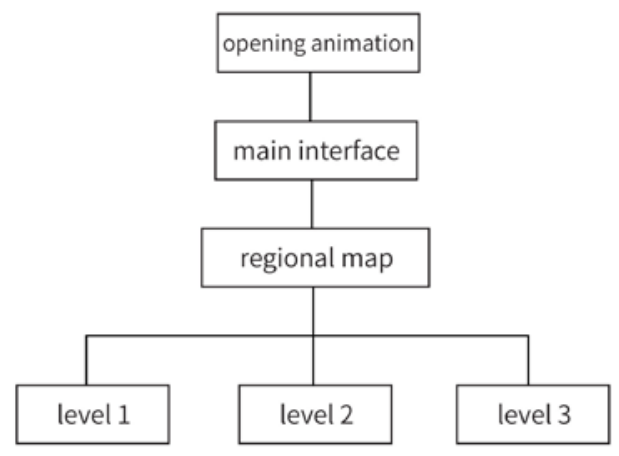

Fig.1. Game framework

\section{Set up Game Levels}

The game sets three levels with same length. The scenes from the first level to the third level are respectively snowfield, desert and grotto, with difficulty in ascending order. The scoring system of the game calculates the accumulative gold coins eaten. In real game, arriving at destination means pass.

\section{Design of the Game Role}

The game is centered on player who interacts with game world through game role. So the way of designing visual model of game role will have a direct influence on game experience of player.

There are a wide variety of Sanxingdui cultural relics, such as ritual ware for sacrificing, bronze ware, pottery and jade ware, etc. After selected, we choose the most representative and best-known bronze mask as major elements of game. Its most distinctive feature is bulging eyes and wide nose, especially bearing exotic characteristics of ancient Shu.

To highlight Sanxingdui culture elements, the design of role fuses bronze human face image into role design as a decoration. The role image learns from mascot friendlies for Beijing Olympic Games, and Sanxingdui mask is worn on the head of role as decoration. The materials superposition 
can make role more lifelike. The color of clothes for the role is taken from Sanxingdui green of Sanxingdui bronze ware. The role setting is as shown in figure 2 .

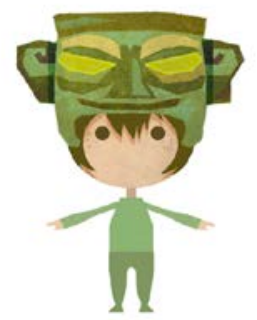

Fig.2. Game framework

According to figure of role setting, the movements of run, jump and drop for protagonist are drawn using Photoshop and then made into frame-by-frame animation. 2D form can give more sense of unity to the general flat style of the game. The role's run movement series drawn frame by frame is as shown in figure 3.

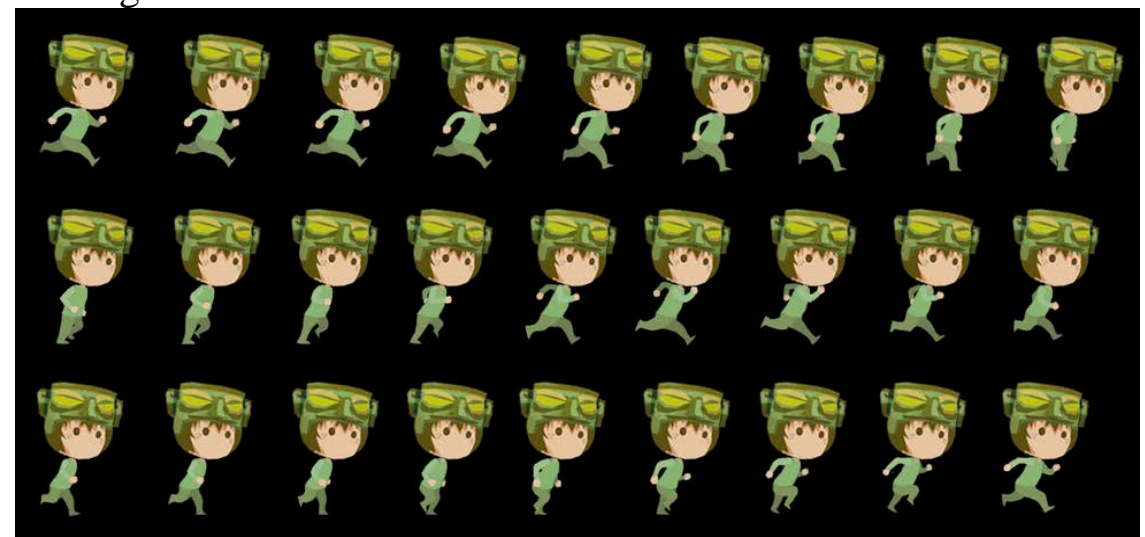

Fig.3. Game role’s running sprite sheets

What follows design of game role and beginning animation is setting of game scene, interface, impediment, and gold coins. A complete game visual system is done by combining these designs, role and beginning animation.

\section{Design of the Game Scenes}

The game altogether has three levels, with the third level set as locked state. The scene style is determined according to the game style set in early planning and style of the game role. As the size of game scene must be determined according to the size of mobile equipment, following figures are respectively the design of the scene concepts for the first and second levels.

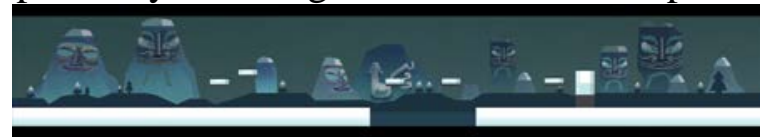

(a) The first level

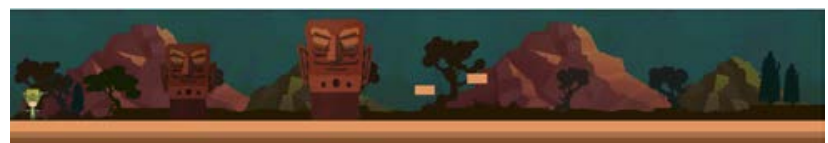

(b) The second level

Fig.4. Concepts of the game scenes

Android's resolution is $1920 * 1080$ pixels. As this is a horizontal version game, the general resolution of one scene is resolution probability of four Androids. With width unchanged, length is fourfold of original one, i.e. the final resolution is $7680 * 1080$ pixels, and total length of scene for each level is the same.

\section{Design of the Game Interface}

Game interfaces mainly include main menu for entering the game, large map, role victory and failure, etc. When designing game interface, not only esthetic appearance is considered, but also 
user's functional experience is taken into account. Generally each interface has corresponding themes and primary functions. And the design of the interfaces must be well organized. Following figures are interface design of the game.

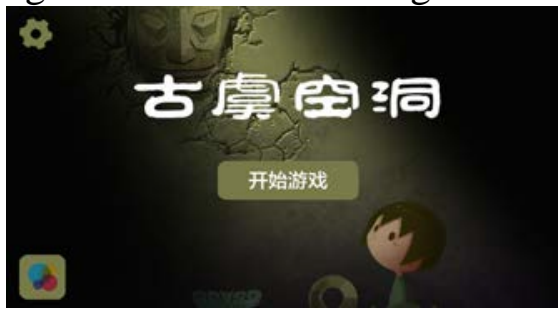

(a) The main interface

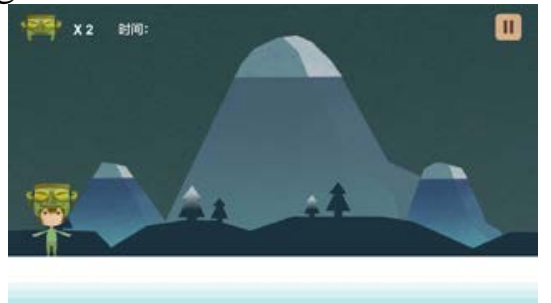

(b) level interface

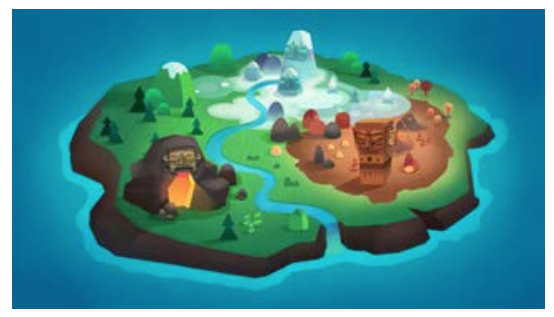

(c) No chip kick mechanics

Fig.5. Concepts of game interface

\section{Design of the Game Props}

During the game process, the player operates the little hero to avoid obstacles, and collects prop of gold coin to pass. The shape of gold coin is set as the shape of sunbird unearthed in Sanxingdui, as sunbird can bring hope in legend. Following figure is setting of gold coin.

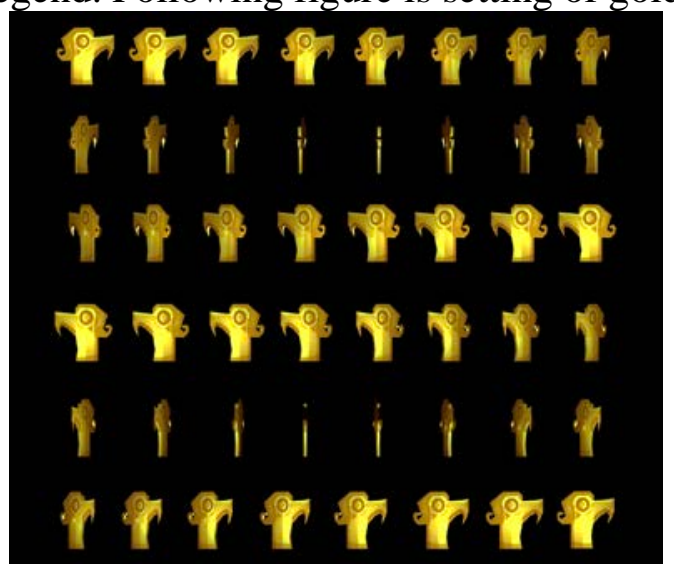

Fig.6. Coin rendering

\section{Game Test Result}

Lastly all elements are integrated by adding game scripts, enabling functions of system scoring, little hero running, and camera following, etc. The game test result is as follow:

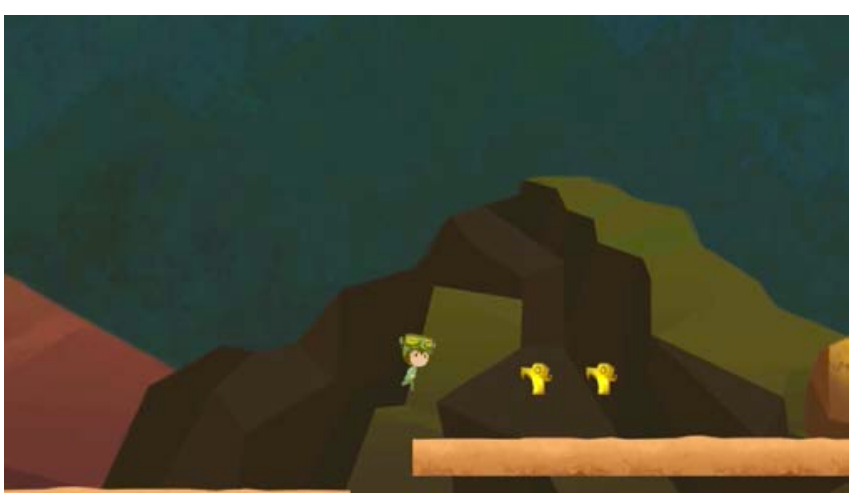

Fig.7. Game test result

\section{Conclusion}

The paper combined Sanxingdui culture elements to fabricate the adventure game entitled Cavity in Ancient $\mathrm{Yu}$, analyzed the whole concrete course from planning, design to realization, and presented a detailed introduction of the Sanxingdui elements used, to provide reference for future development of 2D horizontal adventure game with similar theme of cultural remains. 


\section{References}

[1] Zhu Xue. Research on New Trend of Role Setting in Q-Version Game [J]. Beauty \& Times (part 1). November 2013.

[2] Scott Rogers. Level up! The Guide to Great Video Game Design [M]. Posts \& Telecom Press, 2013.

[3] Song Zhen-hao, Xiao Xian-jin. Yinshang Civilization and Works Commemorating the Seventith Anniversary of Finding Sanxingdui Site [M]. Circulation department of Social Science Academic Press, August 2003.

[4] Kim Chong Kee, Wang Dou-dou. Multimedia Design Basis [M] Shanghai People's Fine Arts Publishing House, 2010.

[5] Liang Lei, Yang Jun-shun, Gou Zhu-quan. A Discussion about Basic Elements in Design of Game Role [J]. Movie Evaluation, issue 18, 2007. 